\title{
EL ARTE DEL DISCURSO PÚBLICO. UNA INVITACIÓN A LA RETÓRICA DE ARISTÓTELES
}

\author{
Luis Vega Reñón \\ Universidad Nacional de Educación a Distancia (UNED) \\ lvegar.academ@gmail.com
}

\section{RESUMEN}

Propongo una lectura de la Retórica (libro I) como presentación del arte del discurso público. En este sentido su concepción descansa en tres ideas capitales: (a) la retórica es antistrofa de la dialéctica; (b) su tarea no es persuadir, sino contemplar los medios disponibles de persuasión en cada caso; (c) es vástago de la dialéctica y del saber ético que cabe llamar justamente política. (a) y (b) vindican la condición y calidad de la retórica como arte con pleno derecho del discurso; (c) la sitúa en el terreno del discurso público deliberativo. Como colofón, unas notas acerca de la actualidad de algunas ideas aristotélicas en el debate sobre democracia y deliberación colectiva moverán a la conclusión de que Aristóteles, sin ser uno de nosotros, es uno de los nuestros.

Palabras clave: Retórica, dialéctica, discurso público, democracia, deliberación colectiva.

THE ART OF PUBLIC SPEECH. AN INVITATION

TO ARISTOTLE'S RHETORIC

\section{Abstract}

I propose to read Rhetoric (B. I) as a presentation of the art of public discourse. I believe that in this sense its conception rests on three capital ideas, namely (a) rhetoric is an antistrophos to dialectic; (b) its function is not to persuade but to contemplate the available means of persuasion in each case; (c) rhetoric is like some offshoot of dialectic and of ethical study which is rightly called politics. (a) and (b) vindicate the condition and quality of rhetoric as a fully entitled art of speech; (c) places it in the realm of deliberative public discourse. Finally, a few notes about the topicality of some Aristotelian ideas in the debate on democracy and collective deliberation will lead to the conclusion that Aristotle, without being one of us, is one of ours.

KEYwORDs: Rhetoric, dialectic, public discourse, democracy, collective deliberation. 
Les propongo releer la Retórica de Aristóteles, el libro i en particular, como una presentación del arte del discurso público ${ }^{1}$. El propio Aristóteles da fe de una tradición anterior de manuales de retórica $(R S \text { 183b34-36) })^{2}$. Aunque no se priva de criticarlos en su perdida compilación Technôn synanoge, al parecer debido a que esos manuales ofrecían muestras de prácticas retóricas, pero no recursos ni procedimientos de elaboración discursiva, menos aún conceptos al respecto. Es una torpeza equivalente a enseñar el ejercicio de un arte limitándose a mostrar sus productos, sin exponer los modos de producirlos o confeccionarlos. Hay una excepción que vendría a confirmar la regla: la Retórica a Alejandro -atribuida a un sofista contemporáneo de Aristóteles, Anaxímenes de Lámpsaco-, que ya tiene hechura de tratado y pasa por ser el más antiguo conservado en nuestros días ${ }^{3}$.

En todo caso hoy contamos con varias muestras supuestamente primerizas de ingenio discursivo como, por ejemplo, la representada por los retóricos Córax y Tisias. Tisias no tiene dinero para pagar las enseñanzas que acaba de recibir de Córax, así que ambos llegan a un acuerdo: las abonará en el momento en que gane su primera causa forense. Pasa el tiempo sin que Tisias se presente en un juzgado; Córax se impacienta y, al fin, lo conmina en estos términos: «Voy a pleitear contigo y entonces habrás de pagarme, bien porque ganas el juicio y has de cumplir la condición acordada o bien porque lo pierdes y has de cumplir la sentencia en tu contra». Tisias no se inmuta y retuerce el dilema: «No tendré que pagarte, bien porque pierdo el juicio y queda en suspenso la condición acordada o bien porque lo gano y tu reclamación resulta desestimada». Llevado el caso ante un tribunal, los jueces, sorprendidos, se limitan a despedir a los dos pleiteantes con el veredicto: «De tal cuervo, tal huevo» ${ }^{4}$.

Antes de entrar en la lectura que propongo de la Retórica no estará de más una observación sobre la propia obra. Como es sabido, no fue un tratado dispuesto por Aristóteles para su publicación en la forma en que la conocemos. Se funda más bien en unos apuntes o notas tomadas para la preparación de sus clases en la Academia y en el Liceo; se trata de un texto esotérico cuya composición se estima en el tercer cuarto del s. Iv, hacia los años 350-30 a.n.e.; su estado actual corresponde básicamente a la edición de Andrónico de Rodas tres siglos después, en el s. I a.n.e. Por otra parte, se compone de estratos, no sin eventuales incongruencias y adiciones, donde el libro i prima los aspectos discursivos del arte de la retórica, mientras que el libro II añade el tratamiento de complementos subjetivos como las afecciones y

${ }^{1}$ El texto corresponde a la IX Conferencia de la Cátedra Cultural Javier Muguerza (Universidad de La Laguna, 2021). Mi enhorabuena a los mantenedores de la Cátedra CJM, Pablo Ródenas Utray y Vicente Hernández Pedrero, y mi agradecimiento por invitarme a intervenir en ella.

2 En las referencias y citas empleo las siglas habituales de las obras aristotélicas: $R S$ para las Refutaciones sofísticas, Rh. para la Retórica, Top. para los Tópicos, APr. para los Primeros Analíticos, EN para la Ética Nicomáquea, Pol. para la Politica.

3 Vid. la edición de SÁnchez Sanz, J. (1989), Retórica a Alejandro, Salamanca: Ediciones Universidad de Salamanca.

${ }^{4}$ Uno de los significados de Córax es precisamente 'cuervo'. No está acreditada la existencia de estos antiguos personajes y, por otro lado, este litigio también se atribuye a Protágoras y a su discípulo Eualto. 
pasiones, y el libro III se ocupa de las figuras y otras cuestiones de estilo. Cabe considerar que el libro I representa un primer estrato -aunque su capítulo 2 responde a la versión final de la obra- y contiene los elementos conceptuales fundamentales del tratado. En este sentido creo que la concepción general de la Retórica aristotélica descansa en tres ideas capitales, a saber:

a) «La retórica es antistrofa de la dialéctica» (Rh. 1354a1), según reza el comienzo del libros.

b) «Sea la retórica la facultad de contemplar [theorêsai] lo adecuado en cada caso para convencer» (1355b25-6). Su tarea «no consiste en persuadir sino en reconocer los medios de convicción pertinentes para cada caso» (1355b1112). Cabe leer esta precisión como la redención metadiscursiva y separación de la Retórica con respecto a la práctica oratoria ordinaria.

c) «La retórica es vástago de la dialéctica y de aquel saber práctico sobre los caracteres [éthe] al que es justo denominar política» (1356a26-27). La declaración no solo amplía el marco de relaciones de la retórica sino que le franquea el paso al dominio del discurso público. Dando un paso más en la misma línea recordemos el papel del rhétor como un ciudadano capaz de intervenir mediante la palabra en el discurso público y por esta vía en la vida pública de la polis.

Es comúnmente reconocido el papel de Aristóteles como padre o fundador de los estudios que constituyen "la teoría» de la argumentación, es decir el campo de la argumentación. Pues bien, esas tres ideas marcan su contribución fundacional a la retórica: (a) y (b) vindican y determinan la condición y calidad de la retórica como arte del discurso; (c), a su vez, da pie para explorar y conceptualizar el área -hasta entonces practicada antes que estudiada- del discurso público, especialmente en el terreno paradigmático del género deliberativo.

1.

Volvamos a la primera idea para precisar la correlación declarada entre la retórica y la dialéctica. En términos esquemáticos se puede establecer la siguiente tabla de similitudes o correspondencias:

(I) Las dos artes discursivas se mueven dentro del ámbito de lo contingente, de lo que puede ser o darse de otra manera, lejos de la necesidad que se supone

${ }^{5}$ El término antistrofa procede de la poesía y del teatro, donde denota una réplica del mismo estilo que la estrofa en la que el coro se mueve del oeste al este o de izquierda a derecha del espectador. Mantengo esta expresión metafórica en vez de su versión como correlato, contrapartida o similar, no solo por el carácter problemático de estas traducciones sino por el detalle interesante de que Platón se sirve de esa misma metáfora para descalificar la retórica y rebajarla al nivel del arte de cocinar (Gorgias, 465d), una práctica empírica y menor a su juicio (pace Paul Bocuse o Ferran Adrià). Aprovecho la ocasión para declararme responsable de las versiones de todos los textos citados. 
inherente a las relaciones lógicas o matemáticas o a los movimientos astrales, por ejemplo.

(II) Ambas tratan con opiniones, de modo que por lo regular han de atenerse a consideraciones plausibles y convincentes.

(III) Las dos son facultades de procurar razones (argumentos [lógous]) (1356a33).

(Iv) No hacen referencia a materias sustantivas o específicas. Tienen, en cambio, una aplicabilidad general y procedimental. Por ende no constituyen ciencias determinadas, sino artes (téchnai), es decir, disciplinas reflexivas, especializadas y susceptibles de aprendizaje.

(v) En ambas cabe argumentar de modo efectivo o argüir de modo espurio y aparente -«sofístico» según el dictamen aristotélico-.

Pero estos emparejamientos no excluyen la existencia de disparidades como las siguientes:

( $\left.{ }^{*}\right)$ La retórica y la dialéctica difieren en sus respectivos propósitos prácticos. El de la primera consiste en persuadir o disuadir al auditorio en una causa forense o en una asamblea. El de la segunda, a tenor de los Tópicos (100²0-23), en no incurrir en inconsistencias en el curso de una confrontación discursiva.

(II*) También son distintos los servicios que se esperan de una y otra: los retóricos tienen que ver con el tratamiento de asuntos humanos, los dialécticos pueden ser más bien teóricos y críticos, o de puesta a prueba (peirásticos) o, en fin, de entrenamiento.

(III*) El medio discursivo propio de la retórica es el discurso público, en dimensión micro, forense, o en dimensión macro, asamblearia, mientras que el característico de la dialéctica es dialógico, e. g., en la modalidad socrática de preguntas y respuestas.

(IV*) La práctica retórica descansa en relaciones interpersonales y presenciales, mientras que la dialéctica también puede darse entre papeles como los de proponente y oponente.

No estará de más insistir en que la correlación aristotélica entre ambas conduce a la vindicación de la retórica como arte, téchne, es decir: no solo una práctica específica sino un saber hacer fundado racionalmente en conocimientos verdaderos (EN 1149a1-22) y por lo tanto capaz de explicar su proceder y justificar sus resultados. Este punto cobrará mayor importancia en el contexto de la puesta en cuestión de la calidad y legitimidad de la retórica como disciplina discursiva. Para hacerse una idea comprensiva al respecto conviene recordar su gestación y desarrollo en la Grecia clásica.

2.

Suele asociarse el origen de la retórica a litigios de propiedad en Sicilia. Pero estas primicias forenses pronto se verán desbordadas por las nuevas necesidades del discurso público en algunas sociedades como la ateniense. El desarrollo sociopolí- 
tico en la Atenas de los ss. vi y v a.n.e. alumbra un nuevo régimen democrático en el que se va conformando el demos -el conjunto de los ciudadanos, varones adultos y libres- como un agente sociopolítico relativamente autónomo, dispuesto a deliberar y decidir colectivamente sobre asuntos de interés común. Antiguamente se decía que todo recién nacido trae un pan bajo el brazo; en un sentido análogo cabe decir que el demos trae consigo la retórica. Con este agente aparece la retórica deliberativa como un modo de intervenir en el discurso público y, a través de él, en la vida política. Luego, durante los ss. v-IV a. n. e., algunos intelectuales como los sofistas y sus competidores -que suelen distinguirse a sí mismos como filósofosvan tomando conciencia de esa forma deliberativa de actuación e intervención en los asuntos públicos, y de los problemas y dificultades que genera como alternativa discursiva y política. Se plantean sobre todo problemas de capacidad y competencia; por ejemplo, cómo es posible tomar decisiones racionales, oportunas y efectivas entre tanta gente, gente para colmo indocumentada.

Es instructiva al respecto la respuesta del sofista Protágoras a una cuestión de este tipo que recoge Platón en el diálogo homónimo (Protágoras 320d-322d). Sócrates pregunta por qué se recurre a los expertos en cuestiones técnicas, e. g., arquitectónicas o navales, pero no cuando se trata del gobierno de la pólis (ciudad-estado), donde las magistraturas se desempeñan por sorteo. Protágoras responde mediante un famoso mito. Según el mito, Zeus ha encargado a Prometeo la distribución de cualidades entre los seres vivos. Prometeo delega la tarea en Epimeteo, un ayudante poco previsor que va prodigando facultades y habilidades hasta verse con las manos vacías cuando llega a los humanos. Así que para compensarles de sus carencias naturales, Prometeo les entrega el suplemento del fuego y de las técnicas. Pero los humanos vienen a caer entonces en disputas y luchas por intereses enfrentados que mueven a Zeus a confiar a Hermes un nuevo reparto esta vez del sentido de la justicia [diké] y de la dignidad o vergüenza [aidós] e igualitario entre todos ellos Pues frente a la anterior distribución desigual de cualidades y recursos, Zeus advierte que los nuevos dones se han de repartir entre todos los humanos sin distinción porque si solo participaran de ellos unos pocos, como ocurre con las demás artes o técnicas especializadas, nunca llegaría a haber ciudades (322c-d).

A partir de ahí quizás sea clarificador plantear y resumir la discusión como si se tratara de una confrontación entre, de un lado, los reparos contra los usos y servicios democráticos del discurso público que abrigan «antidemócratas» tan dispares como Aristófanes, el Viejo Oligarca o Platón y, de otro lado, las réplicas que podría aducir en su caso Aristóteles - sin que ellas lo acrediten como un «demócrata» cabal y convencido-.

Veamos, para empezar, los reparos del bando «antidemócrata». Para estos autores, el tratamiento deliberativo de los asuntos públicos comporta en realidad una mezcla inestable de auditorios incapaces de discernir la verdad y proclives a dejarse engañar, con oradores celosos de oscuros intereses y dados a halagar las pasiones del populacho. Entonces no puede sino violar un supuesto de la buena deliberación política: la prevalencia del saber, esto es, de la verdad y del conocimiento. Un saber que, por cierto, solo es accesible a los expertos, a los filósofos en este caso, pero no a la ciudadanía en general, pues es imposible que la gente en su conjunto sea filósofa 
(Platón, República, 494a). Lejos de atenerse a esta condición epistémica, en la deliberación pública se trata de determinar lo debido (lo honesto, lo justo, lo piadoso) mediante acuerdos mayoritarios (Teeteto 172b), a través de un discurso puramente suasorio y plausible (i. e., sin pruebas efectivas como las del geómetra, ibd. 162e), y por parte de una muchedumbre presa de sus pasiones y atada a sus dispares intereses, pues, en definitiva, la multitud está incapacitada no solo para un conocimiento especializado sino para el uso lúcido y reflexivo de la razón.

Las posibles réplicas aristotélicas discurrirían en tres sentidos. De entrada, habría que distinguir entre el proceder preciso para la demostración de un teorema matemático y el pertinente para la adopción razonable de un curso de acción: tan absurdo sería exigir a un orador demostraciones precisas y categóricas como pedir a un geómetra razones meramente plausibles o persuasivas. Por otro lado, tanto el conocimiento cierto como el plausible suponen el ejercicio de una misma facultad.

Corresponde a una misma facultad reconocer tanto lo verdadero como lo verosímil, y los hombres tienden por naturaleza de modo suficiente a la verdad y la mayor parte de las veces la alcanzan. Así que estar en disposición de discernir acerca de lo plausible es propio de quien está en la misma disposición respecto de la verdad (Retórica, I 1.4, 1355a15-19).

Y, en fin, la retórica, dada su proyección tanto forense como deliberativa, no se reduce a las malas artes de la seducción y la manipulación del público. Antes bien, «[L]a retórica tiene por objeto formar un juicio, dado que también se juzga en las deliberaciones y la propia acción judicial es una acción de juzgar» $(R h$. II 1.1 1377b20-22). Es, en mi opinión, un modo de hacer justicia a los propósitos formativos y educativos de la retórica ilustrada de algunos sofistas, Protágoras en particular, y otros pensadores como Isócrates.

Los reparos de Platón pueden ser más concretos e incisivos al centrarse en la retórica misma. Declara que la retórica es a la justicia lo que el cocinar a la medicina (Gorgias 465c), o también es respecto del alma lo que el cocinar respecto del cuerpo (465d). En suma: la retórica viene a ser antistrofa de la cocina (ibd.), puesto que las dos descansan en la mera experiencia de donde obtienen rutinas o recetas para producir agrado y placer (Gorgias 462e), pero una y otra actividades, la retórica y la culinaria, están lejos de constituir artes o ciencias. Esto es debido a que los retóricos no tienen un objeto susceptible de análisis, ni cuentan con criterios de eficiencia técnica. Su propósito característico es lograr la gratificación y la aprobación del auditorio; en aras de este objetivo, supeditan el interés por la verdad o por lo justo y lo injusto a otros intereses y consideraciones ocasionales y pragmáticas ${ }^{6}$.

${ }^{6}$ En Fedro mostrará una actitud menos sesgada y más ambivalente ante la retórica, capaz de guiar tanto en público como en privado las almas a través de las palabras (261a), siempre que el retórico conozca la naturaleza del alma y atienda al marco y a las circunstancias concretas del discurso (271d-272b). Se trataría de una retórica psicagógica alternativa a la demagógica. 
¿Qué tendría que decir Aristóteles al respecto? Algo que ya conocemos pues se encuentra en las ideas básicas que he avanzado al principio. Ante todo, puede replicar que la retórica viene a ser antistrofa o pareja de la dialéctica, disciplina que, desde luego, merece todo reconocimiento por parte de Platón. Recordemos, además, las similitudes y correspondencias metódicas o de proceder entre ambas.

Pero estas similitudes no ocultan ciertas diferencias en las que conviene insistir. Una diferencia básica estriba en que el dominio de la retórica es el discurso público en la tradición del rhétor no solo como orador más o menos elocuente, sino como portavoz o agente discursivo en asambleas acerca de asuntos de interés común para el colectivo de la ciudad. Según esto, podríamos decir que la retórica es al discurso público lo que la dialéctica es al discurso privado -sea monológico, cuando uno argumenta consigo mismo, o dialógico, cuando un agente discursivo discute con otro según el procedimiento normalizado en los Tópicos-. La referencia al discurso público sitúa la práctica de la retórica en el ejercicio no solo de labores judiciales sino más aún de la política.

Pues bien, esta conexión es la que corresponde a la caracterización de la retórica formulada por Aristóteles donde viene a ser «un vástago de la dialéctica y de aquel saber práctico sobre los caracteres [éthe] al que es justo denominar política» (Rh., 1356a26-27). En términos modernos diríamos entonces que la retórica también es una hijuela de la dialéctica y de una suerte de "política-ética»-«poli(é) tica», cabría decir con Pablo Ródenas-, siempre que se reconozcan las distancias y diferencias de las ideas políticas y éticas aristotélicas con respecto a las nuestras.

Hay, en fin y en esa misma línea, una fundamentación de la competencia discursiva de las comunidades humanas que da respuesta cabal a los negacionistas de la competencia deliberativa del común. No se halla en la Retórica sino en la Politica. Dice:

El hombre es por naturaleza un animal social [politicòn]» (Po., I 1253a2-3). «La razón por la que el hombre es un animal social, más que la abeja o cualquier animal gregario, es evidente: la naturaleza, como solemos decir, nada hace en vano y el hombre es el único animal que tiene lenguaje (logos). La voz es signo de dolor y placer, y por eso la tienen también los demás animales pues su naturaleza les permite sentir dolor y placer e indicárselo unos a otros. Pero el lenguaje es para manifestar lo conveniente y lo perjudicial, lo justo y lo injusto, y es propio y exclusivo del hombre, frente a los demás animales, tener el sentido de lo bueno y lo malo, lo justo y lo injusto, y demás cosas por el estilo, y la comunidad de estas cosas es lo que constituye la casa y la ciudad" (1253a8-18). Y remata su argumentación: como «el individuo separado no se basta a sí mismo, será semejante a las demás partes en relación con el todo, y el que no pueda vivir en sociedad o no necesite nada por su propia suficiencia, no será miembro de la ciudad sino una bestia o un dios (ibid. 1253a19-29).

Así pues, frente a las dudas sobre la competencia deliberativa del démos, de la ciudadanía, resulta que solo los dioses o las bestias serían seres incapacitados o ajenos por naturaleza a la deliberación común. En el antiguo mundo griego -y para el caso, en el nuestro- es difícil declarar con mayor lucidez y fuerza tanto la función y virtud del discurso público como la competencia colectiva para su ejercicio deliberativo. 
Me gustaría terminar con una alusión al tópico de la contraposición: razón vs. emoción + seducción que se ha traducido históricamente en otra oposición disciplinaria: lógica vs. retórica, por un lado y, por otro, ha alimentado la mala prensa de la retórica como ornamento literario o espuma del discurso durante los ss. XVII-XX (1. ${ }^{a}$ mitad), hasta la reivindicación que emprenden Chaïm Perelman \& Lucie Olbrechts-Tyteca (1958), el movimiento de la Nueva Retórica y algún Departamento usamericano de Speech and Communication ${ }^{7}$. Reanimados así, pasemos a considerar otros temas básicos.

3.

Las bases conceptuales sentadas en el libro i de la Retórica se pueden contraer a estos tres tipos: (1) Procedimientos genéricos o comunes de prueba persuasiva. (2) Fuentes específicas de pruebas. (3) Géneros retóricos.

Los procedimientos de tipo (1) son el entimema y el ejemplo. Ya se hallaban reconocidos en la Retórica a Alejandro, el tratado culminante de la tradición anterior a la Retórica de Aristóteles. Pero la obra aristotélica presenta un sesgo inferencial o dialéctico que le da un giro singular, ausente en esa tradición. En principio, el entimema viene a ser un silogismo o inferencia a partir de premisas verosímiles o de signos concluyentes o indicativos (indicios). Es un procedimiento inferencial común, frecuente incluso en medicina. Son muestras aristotélicas: esta mujer tiene secreción de leche en los pechos, luego ha parido; esta persona tiene fiebre alta, luego está enferma. El ejemplo, a su vez, discurre de un caso particular a otro y suele descansar en una relación de semejanza, de modo que solo alcanza a tener una fuerza inferencial no concluyente, plausible. Esta mujer presenta palidez, se marea a menudo y acusa retraso en la regla, así que, a juzgar por casos similares, está embazada. Pero ambos procedimientos merecen más atención.

Enthimèma era un término de uso común para denotar algo que se tiene en mente o en el ánimo (thimós), que adquiere especial relevancia en la tradición retórica y lógica a partir de Aristóteles. Es el silogismo retórico $(R h .1356 b 3-5)$, una deducción a partir de premisas verosímiles o de signos o indicios (APr. 70a10, Rh. 1357a32) y sobre la base de tópicos $(R h .1358$ a30). En un sentido más amplio, también puede inspirarse en ejemplos o paradigmas ( $R h .1402 \mathrm{~b} 14-22)$. Según una famosa metáfora constituye "el cuerpo de la persuasión» (Rh. 1354a15). A la doble luz de los Primeros Analíticos y de la Retórica, parece presentar una suerte de diversificación: analítica, orientada al conocimiento, y retórica, dirigida a la persuasión. En todo caso, se trata de un silogismo peculiar en la medida en que: a/ suele versar sobre cosas contingentes y asuntos de orden práctico; b/ parte de alguna verosimilitud [eicós] o signo

7 Vid. Vega Reñón, L. (2019) La argumentación en la historia. Tres momento constituyentes. Mauritius: EAE-OmniScriptum, parte III, cap. 1 , $\$ 1$, y cap. 3, $\$ 2.1$, pp. 328-338 y 421-427 respectivamente. 
[sēmeîon] y suele apelar a tópicos o apelar a consideraciones plausibles [éndoxa] que se suponen familiares para aquellos a quienes se dirige; c/ aunque corresponda en retórica al silogismo en dialéctica y obre como una suerte de demostración retórica, por lo regular no es concluyente de necesidad; más aún, puede conducir a conclusiones refutables $(R h .1357 \mathrm{a} 23$ ss.). Así pues, difiere tanto textual como contextualmente del silogismo demostrativo canónico (1355a5-14, 1356b5-11).

Otra tradición lógica, de inspiración estoica, acentuará su sentido como argumento de una sola premisa o como «silogismo truncado» al confluir en algunos comentadores ambas fuentes, aristotélica y estoica. Recordemos la muestra escolar: «Sócrates es un ser humano, luego morirá», donde tácitamente se supone: «todo ser humano es mortal». Por desgracia, será esta connotación defectiva la que prevalecerá en la modernidad. La desgracia es doble: reside de una parte en la trivialización de su forma lógica y, de otra parte, en la ignorancia o anulación de su llamado pragmático a la complicidad del interlocutor o del auditorio al que se dirige una argumentación que descansa en sobreentendidos compartidos. El interlocutor o el auditorio es el llamado a completar la argumentación y, en cierto modo, a contribuir por su cuenta como agente discursivo a generar su propia convicción. Al margen de su deficiencia formal, por falta de alguna premisa o suposición expresa, es justamente en la brevedad y en la complicidad cognitiva o conocimiento compartido donde, a juicio de Aristóteles, viene a residir en buena parte su rendimiento retórico. La brevedad viene exigida por la efectividad de la acción y la comunicación retórica, de modo que «no hay que tomarlo todo desde lejos ni tampoco concluir pasando por cada término; lo primero es oscuro por largo; lo otro, charlatanería por decir lo que es evidente» (Rh. 1396b25-27). Y, en fin, la complicidad o participación en el curso de una inferencia en la que no es preciso declarar algo ya sabido (pues «el propio oyente lo pone», $R h$. 1357a17-21), actúa como un refuerzo de la persuasión ("porque los oyentes se sienten ellos mismos satisfechos de lo que han previsto", $R h .1400 \mathrm{~b} 32-3$ ).

Por su parte, parádeigma venía siendo un término habitual en las artes con el sentido de plano de arquitectura (Heródoto, 5.62), modelo de pintura (República $500 \mathrm{~b}$ ) o de escultura (Timeo, 28c), que pasa a tener un significado metódico de ejemplo de apelación o de referencia en medios retóricos forenses o deliberativos. Para Aristóteles representa una suerte de inducción retórica $(R h .1356 \mathrm{bl}-6)$ que obra por analogía (APr. 68b38-41) o discurre de un caso particular a otro caso similar. Más precisamente, discurre no como la parte respecto del todo, ni como el todo respecto de la parte, ni como el todo respecto del todo, sino como la parte respecto de la parte y lo semejante respecto de lo semejante $(R h .1357 \mathrm{~b} 28-30)$. Por otro lado, puede consistir en hechos reales, sucedidos, o en símiles ficticios -como las fábulas o las parábolas- (Rh. 1393a29-30). En el primer caso y en especial dentro de un marco deliberativo, su eficacia probatoria también descansa en un supuesto del tenor de: «en la mayoría de los casos, lo que venga será similar a lo ya acaecido» (Rh. 1394a7), pero supone que los casos considerados son del mismo género y uno es más conocido que el otro (Rh. 1357b30-31). Así, para probar que Dionisio intenta la tiranía al pedir una escolta armada, cabe argumentar por esta vía del ejemplo aduciendo que otros que la habían pedido como Pisístrato o Teágenes, tras conseguirla, se hicieron tiranos (ibid. 1357b32-35). Los principales paralelismos a los que da lugar vienen 
a ser de tres tipos: referidos a hechos históricos, a las artes y las técnicas, a fábulas -en particular, apólogos de animales- (Rh. 1393a22-1394a18). Su poder de convicción es menor que el de los entimemas, pero no deja de tener con ellos relaciones tácticas de modo que conviene aducir muchos casos ejemplares antes de la prueba principal para provocar un efecto inductivo, pero después de esa prueba, basta uno en calidad de evidencia testimonial o concreta (Rh. 1394a14-18).

El empleo general y común de entimemas y ejemplos con fines inferenciales ha dado lugar a la consideración de una suerte de universales retóricos. En concreto, Keith Lloyd (2011) ha propuesto su existencia a la luz de una sincronía entre la Retórica de Aristóteles y el Nyāyā Sutra de Gautama, que parece implicar «la presencia de ciertos "universales" retóricos como el razonamiento en el formato aseveración/ razón y la referencia a ejemplos» ${ }^{8}$. Paso el asunto a los interesados en cuestiones de este tipo, no solo filosóficas y antropológicas sino, a mi juicio, un tanto especulativas.

\section{PROCEDIMIENTOS O FUENTES ESPECÍFICAS DE PRUEBA}

Dentro de este tipo cabe distinguir los ajenos al arte y los propios del arte. Los primeros están disponibles al margen del ejercicio retórico del orador: consisten en testimonios, confesiones de esclavos bajo tortura, leyes, contratos, juramentos. Son recursos que se usan.

Los propios del arte son, en cambio, los debidos a las prácticas discursivas del orador, digamos $\log o s_{0}$, en el curso de su actuación retórica. Son recursos que se hacen. A saber: el éthos o talante ${ }^{9}$ del orador, el páthos o disposición del receptor (tribunal, auditorio) y el lógos la exposición y argumentación por parte del rhétor. Daré la palabra a Aristóteles para expresar su motivación.

Puesto que la retórica tiene por objeto formar un juicio [...], es preciso atender no solo a cómo sea demostrativo o digno de crédito el discurso, sino también a cómo ha de presentarse uno mismo (i.e. el hablante) y a cómo ganarse al que juzga (el auditorio)» (II.1 1377b20-24). Según esto: «De entre las pruebas retóricas, las que pueden obtenerse mediante el discurso son de tres especies: unas residen en el talante] del que habla, otras consisten en poner en cierta disposición al oyente y las últimas en el discurso mismo] por lo que este demuestra o parece demostrar. Pues bien, «se prueba» por el talante cuando el discurso es dicho de tal forma que hace al orador digno de crédito. [...] Por otro lado, «se prueba mediante la disposición» de los oyentes, cuando estos son inducidos a un estado de ánimo "propicio" a través del discurso. [...] En fin, los hombres se persuaden por el discurso cuando les mostramos la verdad o lo que parece serlo a partir de lo convincente en cada caso (1.2 1356a1-19).

8 Vid. Lloyd, K. (2011), «Culture and Rhetorical Patterns. Mining the rich relations between Aristotle's Enthymeme and Example and India's Nyāyā Method» Rhetorica, 29/1: 81.

9 Recordemos los dos sentidos de talante según el DLE, ambos pertinentes aquí: 'modo o manera de ejecutar algo' y 'semblante, disposición personal'. 
Hay tres puntos de importancia en este planteamiento:

a) El propósito de la interacción retórica no es meramente emotivo, sino también cognitivo: la retórica tiene por objeto la formación de un juicio por parte de aquellos a quienes se dirige el discurso.

b) Todas sus pruebas propias [por el èthos, el páthos o el lógos] obran a través del discurso $\left[\log o s_{0}\right]$, así que conviene distinguir entre este ${\log o s_{0}}_{0}$ discurso básico, el lenguaje de la comunicación y el entendimiento, y el logos ${ }_{1}$ argumentativo, el discurso específicamente retórico de unas pruebas suasorias o «demostrativas» como el entimema o el paradigma.

c) Los tres tipos de pruebas actúan conjuntamente, no disyuntivamente, de modo que los procesos de inducción retórica implican a los agentes discursivos, hablantes y oyentes, en su integridad, no una facultad en particular (e.g., la racional o la emotiva).

Este punto c/ previene contra las oposiciones al uso que categorizan y separan indebidamente el claro rigor del lógos de la oscura trama del èthos y páthos en la retórica. Al mismo tiempo nos ahorra la discusión de cuestiones ociosas, como, por ejemplo, ¿bastaría servirse del lógos argumentativo o del èthos, o también se precisa la complicidad del páthos? Conforme a cl, está claro que ninguno de los tres tipos de prueba es suficiente por sí solo y todos ellos resultan no solo convenientes y coadyuvantes sino necesarios, aunque puedan obrar con distinto grado de incidencia según sea el caso.

\section{GÉNEROS RETÓRICOS}

Según una tradición presente en Aristóteles hay tres géneros retóricos: el deliberativo, aplicado a aconsejar o desaconsejar cursos de acción futuros; el judicial, especializado en dictaminar hechos pasados a través de las alegaciones de acusación y defensa; y el epidíctico, dedicado a encomiar o censurar personajes o hechos de especial relevancia para el presente.

Valga como presentación comprensiva y sintética en la Retórica el siguiente cuadro esquemático de los tres géneros: $[\alpha]$ deliberativo (dēmēgorikón, simbouleutikón), [ $\beta]$ judicial (dikanikón), $[\gamma]$ epidíctico o ceremonial (epideiktikón), con arreglo estos criterios de distinción: (I) tipo de discurso, (II) marco del discurso, (III) objeto de determinación, (Iv) tiempo de referencia, (v) proceder argumentativo típico.

[a] deliberativo

(I) deliberación para tomar una decisión o resolución

(II) asamblea

(III) conveniente, perjudicial en asuntos públicos [ß] judicial

juici

tribunal

justo, injusto inocencia, culpa $(\gamma)$ epidíctico

elogio, vituperio

ceremonia o

celebración

virtud, valor, belleza y sus contrarios 
(IV)

(v)

$\begin{array}{ccc}\text { acción futura } & \begin{array}{c}\text { acciones } y \\ \text { hechos pasados }\end{array} & \text { momento presente } \\ \text { suasorio/disuasorio } & \text { acusación/defensa } & \text { amplificación } \\ \left.\mathrm{L}_{\text {entimemas y ejemplos }}\right\lrcorner & \end{array}$

Parece ser mayor la importancia del género deliberativo en la Retórica aristotélica y, en particular, de la oratoria política frente a la judicial: se atiene más al asunto tratado y se presta menos a subterfugios ( $c f$. contraste entre la oratoria política y la judicial en $R h .1354 \mathrm{~b} 23-1355 \mathrm{a} 4)$. Sin embargo, en la práctica oratoria no dejan de introducirse en el marco deliberativo otros motivos forenses o apologéticos. En cualquier caso, no debería tomarse la clasificación aristotélica como una taxonomía rígida de géneros estancos.

La retórica deliberativa está, como ya sabemos, directamente involucrada en los usos políticos del discurso público. Su propósito es persuadir de lo conveniente y disuadir de lo perjudicial en determinados asuntos de interés común para el conjunto de la ciudad. Pues, según advierte Aristóteles, no deliberamos sobre cualquier cosa. Deliberamos sobre lo que depende de nosotros y nos concierne. Así que no deliberamos sobre lo necesario, lo inmutable o lo eterno, pues todo esto sobrepasa nuestra capacidad de acción. Tampoco deliberamos sobre el puro azar porque ocurre al margen de nuestros medios de control y posibilidades de intervención. Y, en fin, una comunidad de ciudadanos tampoco delibera sobre lo que no le concierne como, por ejemplo, una constitución política ajena. Su temática cubre en general cuestiones prácticas de interés y de dominio públicos. En particular tiende a tratar asuntos relativos a la adquisición de recursos, la guerra y la paz, la defensa del territorio, las importaciones y exportaciones, la legislación.

Por otro lado, tal deliberación se mueve en el mundo de las opiniones plausibles, es decir más o menos acreditadas socialmente, y, en esta línea, suele remitirse a ciertas máximas o lugares comunes de dominio público ${ }^{10}$. Sus proposiciones hacen referencia a lo que ocurre por lo regular o con frecuencia, a casos o situaciones cuyo desenlace es incierto o comporta cierta indeterminación. Las propuestas que son objeto de deliberación versan sobre lo actuable (praktá), factible o realizable por nosotros mismos -más precisamente por los miembros de la comunidad involucrada-, y se ocupan de modo característico de los medios conducentes al objetivo propuesto conforme a unos esquemas de razonamiento práctico en la línea medios-fines.

10 Las opiniones plausibles [éndoxa] son aquellas que «parecen bien a todos o a la mayoría o a los sabios y, entre estos, a todos, a la mayoría o a los más conocidos y reputados» (Tópicos, 100b21-23). 
Es obligado redondear esta invitación a la Retórica con unas notas sobre su actualidad.

El punto de partida es obviamente el reconocimiento de las diferencias y distancias que separan el mundo aristotélico del nuestro y, en consecuencia, su perspectiva discursiva y sus recursos deliberativos de los nuestros. Baste comparar la extensión de la polis, que se extendía hasta donde llegaba la voz del heraldo, con el alcance planetario de nuestras redes sociales y nuestros dispositivos informáticos. La retórica en aquel medio aristotélico no pasaba de ser una comunicación interpersonal y presencial; la nuestra puede servirse no solo de personalidades que discurren mediante interfaces en espacios virtuales bajo protocolos IP, sino de bots y réplicas automáticas. Si, según el antiguo proverbio que evocaba Aristóteles, «la vergüenza está en los ojos», de modo que en la comunicación interpersonal no dejamos de sentirnos responsables ante la mirada de los otros, nuestra intercomunicación telemática resulta desvergonzada y con frecuencia irresponsable. En la perspectiva de la deliberación la disparidad también es acusada. Por ejemplo, a Aristóteles le movían intereses más bien descriptivos y taxonómicos, muy alejados tanto de los programas macrodeliberativos que alimentan el ideal político de una democracia deliberativa, como de los ensayos y ejercicios microdeliberativos de deliberación democrática que pueden practicar colectivos acotados y reducidos (e. g., los miembros de un jurado, una junta de vecinos, una facultad, una empresa o un municipio). Pero, aparte de las distancias y las diferencias, también cabe reconocer la oportunidad y la significación de algunas sugerencias aristotélicas en nuestro tiempo. Me limitaré a recordar algunas relativas a la recidiva cuestión de la contraposición entre la sabiduría experta y la colectiva ${ }^{11}$. Pueden concretarse a través de ciertos factores influyentes en la calidad y el rendimiento de la interrelación deliberativa con miras a tomar decisiones, como los considerados en la Política.

1. El factor numérico o agregativo. Los muchos deciden mejor que unos pocos-aunque sean expertos- porque al operar conjuntamente reúnen mayor riqueza de medios, fuerza, inteligencia, virtud o cualquier otro criterio básico a la hora de fundamentar una decisión sabia conjunción de medios y habilidades varias. A lo que se ańade su mayor resistencia a la corrupción. En palabras de Aristóteles:

En cuanto a las cuestiones que la ley no puede decidir en absoluto o no puede decidir bien, ¿deben estar al arbitrio del mejor o al de todos? En la actualidad todos reunidos juzgan, deliberan y deciden, y estas decisiones se refieren todas a casos

${ }^{11}$ Supongo que a estas alturas nadie negará la existencia de una sabiduría colectiva. Los más reticentes pueden empezar a despejar sus dudas con el ya «clásico» Surow Recki, J. (2005), The Wisdom of Crowds, New York: Doubleday. Pero se trata de un reconocimiento antiguo, del que hay trazas en la Atenas clásica y que halla expresión en la Política de Aristóteles. 
concretos. Sin duda cada uno de ellos, tomado individualmente, es inferior al mejor, pero la ciudad se compone de muchos y por la misma razón que un banquete al que muchos contribuyen es mejor que el dado por uno solo, también juzga mejor una multitud que cualquier individuo. Además, un gran número "de ciudadanos» es más difícil de corromper, por ejemplo una gran cantidad de agua se corrompe más difícilmente que una pequeña, y así una muchedumbre es más incorruptible que unos pocos [...]. Supongamos que haya cierto número de hombres y ciudadanos buenos: ¿será más incorruptible el gobernante individual o el número mayor de hombres todos buenos? Evidentemente el número mayor. Podrá replicarse que en el número mayor surgirán disensiones, cosa que no puede ocurrir si se trata de uno solo. Pero a esto cabe responder que son de alma recta, como aquél «que era el» único (Pol. 1286a24-1286b3).

2. El factor de pluralismo y heterogeneidad. Asociado al anterior. Aristóteles da a entender que los muchos cuentan no solo con más puntos de vista, sino más variados, así como con argumentos diversos que cabe contrastar y refinar en el curso de debates y procesos deliberativos. ¿Podría ser una anticipación de la capacidad de la deliberación común para neutralización sesgos y prejuicios parciales? ${ }^{12}$.

3. El factor judicativo y evaluativo. A pesar de las limitaciones de la inexperticia de cada individuo, el conjunto de los implicados puede juzgar y evaluar el resultado y el impacto de las decisiones que les afectan, mejor que los expertos que las han tomado. El usuario puede juzgar mejor que el artífice del producto o el vendedor del producto.

Pues cada individuo será peor juez que los expertos, pero todos juntos serán mejores o al menos no peores; y también porque de algunos cosas el que las hace no es el único juez ni el mejor; [...] por ejemplo, juzgar una casa no es asunto solo de quien la ha construido, sino que la juzga mejor incluso el que la utiliza (el dueño); y juzga mejor un timón el piloto que el carpintero, y un banquete los invitados, pero no el cocinero (Pol. 1282a16-23).

La efectividad de estos factores descansa en determinados supuestos como el alma recta y la prudencia de los muchos, su aspiración al bien común como fuente de la felicidad individual y la educación democrática fomentada por la experiencia del gobierno por turno, donde los ciudadanos asumen la doble condición de gobernar y ser gobernados (Pol. 1317b2-3). Tiene interés, en fin, reparar en la corroboración que investigaciones actuales sobre la inteligencia colectiva y el rendimiento del grupo han venido a dar a la clara intuición aristotélica de que los muchos (una comunidad) pueden ser en determinadas condiciones deliberativas agentes resolutivos más fiables y acertados que los expertos. Distingamos, por ejemplo, entre el

12 La importancia de la composición plural y heterogénea del grupo deliberativo para evitar sesgos y puntos ciegos en la discusión y resolución viene mereciendo espacial atención desde el estudio pionero de JANIs, I.J. (1872), Groupthink. Boston: Houghton Mifflin. 
rendimiento individual en la resolución de problemas o toma de decisiones acertadas (la tasa de aciertos de cada individuo), el rendimiento individual promedio (la tasa media de acierto de los componentes del grupo), el rendimiento individual máximo (la tasa del individuo mejor dispuesto y más inteligente) y el rendimiento colectivo (los aciertos de las resoluciones del grupo en su conjunto). Pues bien, hoy sabemos que, en determinadas condiciones, la inteligencia colectiva resulta superior a la inteligencia individual promedio y a la máxima en la medida en que tiene mayor poder predictivo debido al llamado factor c, un factor complejo que incluye: $1 /$ sensibilidad y percepción social («saber leer en la cara o en los gestos»); 2/ distribución paritaria de las intervenciones; $3 /$ alto porcentaje de miembros que muestren una actitud más cooperativa que competitiva («saben escuchar») ${ }^{13}$, a lo que cabe añadir su conformación plural y heterogénea para prevenir sesgos. Se trata, una vez más, de la vieja intuición de Aristóteles en la Política (1282a18-24, 1286a24-40): un grupo puede resultar más capaz y fiable que su miembro más capacitado, consideración que cabe extender al caso de los colectivos o las comunidades y los comités de expertos.

Espero, en fin, que esta presentación de la Retórica como arte del discurso público los y las invite a estimar, por una parte, el gran valor no solo estético y emotivo sino cognitivo y judicativo de esta disciplina humanística en la esfera pública de discurso y, por otra parte, a reconocer que su autor, Aristóteles, no es ciertamente uno de nosotros pero sí es, desde luego, uno de los nuestros.

RECIBIDO: octubre 2021; ACEPTADO: octubre 2021

13 Véase Wolley, A.W. et al. (2010) «Evidence for a collective intelligence factor in the performance of human groups», Science, 330: 686-688. Resultados corroborados en un estudio posterior: Wolley, A.W. et al. (2015), "Collective intelligence and group performance», Current Directions in Psychological Science, 24/6: 420-424. Otro punto notable es la constitución de esta inteligencia colectiva como una propiedad emergente, sobre la base de la composición del grupo y la interacción de sus miembros. 
